\title{
Anti-inflammatory activities of Gardenia jasminoides extracts in retinal pigment epithelial cells and zebrafish embryos
}

\author{
JIANRONG CHEN ${ }^{1}$, GABRIEL MBUTA TCHIVELEKETE ${ }^{2}$, XINZHI ZHOU $^{2}$, WEIZHUO TANG $^{1}$, \\ FANG LIU ${ }^{1}$, MINZHUO LIU ${ }^{1}$, CHENXI ZHAO ${ }^{1}$, XINHUA SHU $^{2-4}$ and ZHIHONG ZENG ${ }^{1,5}$ \\ ${ }^{1}$ College of Biological and Environmental Engineering, Changsha University, Changsha, Hunan 410022, P.R. China; \\ Departments of ${ }^{2}$ Biological and Biomedical Sciences and ${ }^{3}$ Vision Science, Glasgow Caledonian University, \\ Glasgow, G4 0BA, UK; ${ }^{4}$ School of Basic Medical Sciences, Shaoyang University, Shaoyang, Hunan 422000; \\ ${ }^{5}$ Hunan Provincial Key Laboratory of Nutrition and Quality Control Aquatic Animals, Changsha, Hunan 410022, P.R. China
}

Received July 10, 2020; Accepted March 19, 2021

DOI: $10.3892 /$ etm.2021.10132

\begin{abstract}
Age-related macular degeneration (AMD) is the most common cause of visual impairment in developed countries. Inflammation serves a critical role in the pathogenesis of AMD. Gardenia jasminoides is found in several regions of China and is traditionally used as an organic yellow dye but has also been widely used as a therapeutic agent in numerous diseases, including inflammation, depression, hepatic and vascular disorders, which may reflect the variability of functional compounds that are present in Gardenia jasminoides extracts (GJE). To investigate the therapeutic potential of GJE for AMD, ARPE-19 cells were treated with lipopolysaccharide (LPS) or LPS plus GJE. GJE significantly decreased LPS-induced expression of proinflammatory cytokines, including IL-1 $\beta$, IL- 6 and TNF- $\alpha$. In the in vivo study, GJE inhibited CuSO4-induced migration of primitive macrophages to the lateral line in zebrafish embryos. GJE also attenuated expression of cytokines (IL-1 $\beta$, IL-6 and TNF- $\alpha$ ), NFKB activating protein (nkap) and TLR4 in ARPE-19 cells. The results of the present study demonstrated the anti-inflammatory potential of GJE in vitro and in vivo, and suggested GJE as a therapeutic candidate for AMD.
\end{abstract}

\section{Introduction}

Age-related macular degeneration (AMD) is recognized as a serious and rapidly growing worldwide public health concern

Correspondence to: Professor Xinhua Shu, Department of Biological and Biomedical Sciences, Glasgow Caledonian University, 70 Cowcaddens Road, Glasgow G4 0BA, UK

E-mail: Xinhua.Shu@gcu.ac.uk

Professor Zhihong Zeng, College of Biological and Environmental Engineering, Changsha University, 98 Hongshan Road, Changsha, Hunan 410022, P.R. China

E-mail: Z20181201@ccsu.edu.cn

Key words: age-related macular degeneration, inflammation, retinal pigment epithelial cells, zebrafish embryos, Gardenia jasminoides and is the third leading cause of blindness after glaucoma and cataracts (1). The prevalence of AMD by 2040 is projected to significantly increase to 288 million cases (2). Different factors may contribute toward AMD, including age, environmental factors and genetic susceptibility. Ageing may strengthen the problem of visual difficulty associated with AMD. Patients with AMD have extracellular deposits called drusen, which are accumulated within Bruch's membrane (BrM) located between retinal pigment epithelium (RPE) and the choroid. AMD is classified according to age-related eye disease study based on the amount of drusen and it includes early AMD, intermediate AMD and late AMD (3). The late $\mathrm{AMD}$ is sub-divided into the dry non-neovascular type distinguished by the existence of drusen spreading in the central macula, and the wet neovascular type characterized by neovascularization within sub-RPE and sub-retinal space (4). The progression of neovascular AMD may be decreased by injecting anti-VEGF agents into the vitreous humour monthly (5). However, at present, there is no standard medical treatment for dry non-neovascular AMD. Development of novel therapeutic strategies is therefore urgently required.

Inflammation serves a vital role in the pathogenesis of AMD (6). A recent study has reported that plasma levels of interleukin (IL)-6, IL-8 and tumor necrosis factor-alpha (TNF) $\mathrm{R} 2$ are significantly higher in patients with dry AMD than in healthy controls (7). Additionally, the IL-6 level is also associated with the progression of geographic atrophy (7). In wet AMD, IL-1 $\beta$, IL- 6 and TNF- $\alpha$ levels in plasma are significantly high, compared with healthy controls (8). Patients with wet AMD also have an increased expression of inflammation-associated chemokines (CXCL7, 10, 14, 16 and 22) in the aqueous humor (9). NLRP3 inflammasome is upregulated in macular lesions of patients with dry and wet AMD (10). Analyses of plasma complement components have demonstrated systemic complement activation being associated with AMD (11-14). The RPE is responsible for the maintenance of photoreceptor function, and RPE dysfunction is the primary cause of AMD. Inflammation may be induced in the RPE under stress conditions (6). Recently, it was demonstrated that oxidative stress-induced inflammation in RPE cells, indicated by a significant increase in the secretion of IL-1 $\beta$, IL-6, IL- 8 , TNF- $\alpha$ and 
$\operatorname{VEGF}(15,16)$. The RPE is the main cause of drusen formation, and numerous constituents of drusen deposits are inflammation mediators (17). For example, oxidized low-density lipoprotein (oxLDL) may activate inflammasome and increase secretion of proinflammatory cytokines in human RPE cells $(18,19)$. 7-ketocholesterol $(7 \mathrm{KC})$ is another component of drusen, which also induces inflammation in human RPE cells by upregulating the expression of IL-1 $\beta$, IL-6, IL- 8 and TNF- $\alpha(20,21)$.

Gardenia jasminoides (G. Jasminoides, 'Zhi Zi' in Chinese) is an evergreen shrub with fragrant white flowers, which grows in numerous regions of China and is predominantly used as an organic yellow dye (22). The fruits of G. Jasminoides are rich in antioxidant and anti-inflammatory compounds and have been used as a dietary supplement in Chinese herbal medicine for many years to treat a variety of human diseases, including headache, fever, liver disease and hypertension (23). A total of 35 iridoid glycosides and 8 corcin and its derivatives have been identified in G. Jasminoides fruits. The functions of certain identified constituents have been characterized and demonstrated to have antioxidant, anti-inflammatory, anti-diabetic and anticancer activities $(22,24)$.

We hypothesised that G. Jasminoides extract (GJE) may have therapeutic potential for AMD. The present study assessed the efficacy of GJE against inflammation in human RPE cells in vitro and in Zebrafish embryos. It was found that GJE decreased lipopolysaccharide (LPS)-induced inflammation in human RPE cells. It was also demonstrated that GJE inhibited LPS and CuSO4-induced inflammation in Zebrafish embryos.

\section{Materials and methods}

Preparation of G. Jasminoides extract. The dried fruits of G. Jasminoides were collected in October 2017 from a local farm in Yueyang, Hunan, P.R. China. The dried fruits were ground into powder, which was passed through a 40-mesh sieve. A total of $50 \mathrm{~g}$ powder was extracted with $500 \mathrm{ml}$ $75 \%$ ethanol by microwave extraction at $60^{\circ} \mathrm{C}$ for $30 \mathrm{~min}$. The obtained extract solutions were filtered and evaporated under a reduced pressure at $40^{\circ} \mathrm{C}$ to remove the solvents. The dried GJE was dissolved in methanol at $500 \mu \mathrm{g} / \mathrm{ml}$ and filtered through a $0.22 \mu \mathrm{m}$ pore size member for further analysis.

High-performance liquid chromatography (HPLC) analysis. The HPLC separation was performed using a Waters WATO54275-C18 column (250x4.6 mm, $5 \mu \mathrm{m}$, Waters China, Ltd.) installed on a Waters 2695 HPLC instrument (Waters Corporation). The mobile phase consisted of $0.1 \%$ phosphoric acid (A) and acetonitrile (B) with a gradient elution: 0-15 min, 4-25\% B; 15-20 min, 25-28\% B; 20-40 min, 28-38\% B; 40-41 $\mathrm{min}, 95 \% \mathrm{~B} ; 41-51 \mathrm{~min}, 95-4 \% \mathrm{~B}$. The flow rate was $1 \mathrm{ml} / \mathrm{min}$, and the injection volume was $10 \mu \mathrm{l}$. The temperature of the column was set at $25^{\circ} \mathrm{C}$. Standard compounds, including geniposidic acid, deacetylasperulosidic acid, genipin-1-gentiobioside, geniposide, crocin I and II with $>98 \%$ purity were purchased from Shanghai Yuanye Bio-Technology Co., Ltd.

Cell viability. ARPE-19 cells (human retina pigment epithelium cells) were purchased from ATCC (ATCC ${ }^{\circledR}$ CRL-2302 ${ }^{\mathrm{TM}}$ ) and cultured in 96-well plates at a density of $5 \times 10^{4}$ cells/well in DMEM/F-12 (Thermo Fisher Scientific, Inc.) at a final volume of $100 \mu \mathrm{l}$ at $37^{\circ} \mathrm{C}$ in $95 \%$ air and $5 \% \mathrm{CO}_{2}$. A total of $24 \mathrm{~h}$ later, the cells were washed twice with $1 \mathrm{X}$ PBS and treated with LPS dissolved in water at different concentrations: 0, 1.0, 2.5, 5.0, 10.0 and $20 \mu \mathrm{g} / \mathrm{ml}$, with or without GJE dissolved in methanol at concentrations of 5, 10, 25, 50 and $100 \mu \mathrm{g} / \mathrm{ml}$ for $24 \mathrm{~h}$. Subsequently, the cells were washed with 1X PBS twice and treated with serum-free medium containing $0.5 \mu \mathrm{g} / \mathrm{ml}$ MTT (Sigma-Aldrich; Merck KGaA) with the final volume of $50 \mu \mathrm{l}$ per well for $2 \mathrm{~h}$. Next, the MTT solution was removed from the plate, and $100 \mu \mathrm{l} /$ well dimethyl sulfoxide was added. The concentration of formazan was evaluated using an EPOCH microplate reader at $570 \mathrm{~nm}$. The percentage of live cells was calculated using the following formula: $\%$ of viable cells $=(\mathrm{OD}$ of treated cells $/ \mathrm{OD}$ of control cells $) \times 100$.

Zebrafish embryo treatment. All the animal experimental procedures were approved by the Animal Ethics and Welfare Committee, Glasgow Caledonian University (Project License PPL 60/4169). Breeding was set up in the Animal Unit at Glasgow Caledonian University using adult wild-type and transgenic zebrafish (Tg:zlyz-EGFP) expressing EGFP in primitive macrophages to get fertilized embryos, which were maintained in E3 medium consisting of $5 \mathrm{mM} \mathrm{NaCl}, 0.17 \mathrm{mM} \mathrm{KCl}, 0.33 \mathrm{mM}$ $\mathrm{CaCl}_{2}$ and $0.33 \mathrm{mM} \mathrm{MgSO}_{4}(25) . \mathrm{CuSO}_{4}$ has been used to induce acute inflammation, as previously described (26-28). A total of 24 transgenic zebrafish (Tg:zlyz-EGFP) embryos at $48 \mathrm{~h}$ post-fertilization (hpf) were treated with or without GJE (diluted in E3 medium, $5 \mu \mathrm{g} / \mathrm{ml}$ ) for $24 \mathrm{~h}$ (i.e. until $72 \mathrm{hpf}$ ). Zebrafish embryos were further treated with CuSO4 $(20 \mu \mathrm{M})$ for $1 \mathrm{~h}$ to induce the acute inflammation, by adopting the previously reported protocol $(26,27)$. Following treatment, embryos were fixed at room temperature for $2 \mathrm{~h}$ in $4 \%$ paraformaldehyde, and macrophage migration to the lateral line was examined using fluorescent microscopy (magnification, x100). Additionally, the embryos were collected for further gene expression analysis. Lipopolysaccharides (LPS) have also been commonly used to induce inflammation in zebrafish (26-29), and this method was also used in the present study. Wild-type zebrafish embryos at $48 \mathrm{hpf}$ were treated with GJE $(5 \mu \mathrm{g} / \mathrm{ml})$ only, or with GJE plus LPS $(5 \mu \mathrm{g} / \mathrm{ml})$ for $24 \mathrm{~h}$. Following the treatment, embryos were collected and subjected to gene expression analysis.

Reverse transcription-quantitative polymerase chain reaction $(R T-q P C R)$. Total RNA was extracted from treated and control cells or zebrafish embryos using TRIzol ${ }^{\circledR}$ (Sigma-Aldrich; Merck $\mathrm{KgaA}$ ), according to the manufacturer's protocols. High-capacity cDNA Reverse Transcriptase kit (Thermo Fisher Scientific, Inc.) was used for cDNA synthesis, according to the manufacturer's protocols. The RT-qPCR assay was used to quantify gene expression using 5X HOT FIREPol EvaGreen qPCR Mix Plus (ROX) kit (Solis Biodyne) with $12.5 \mathrm{mM} \mathrm{MgCl}_{2}, 10 \mathrm{mM}$ dNTPs, according to the manufacturer's protocols. Reactions were performed in triplicates with a total volume of $10 \mu \mathrm{l}$ consisting of $5.5 \mu \mathrm{l}$ nuclease-free water, $2 \mu \mathrm{l}$ EvaGreen, $0.75 \mu \mathrm{l}$ $10 \mu \mathrm{M}$ forward and reverse primers and $2 \mu \mathrm{l}$ cDNA (60-120 ng). For the control, all reagents were used except cDNA, which was replaced with an equal volume of nuclease-free water. The reaction was performed in the CFX96 Real-time PCR detection system (Bio-Rad Laboratories, Inc.) under the following conditions: Denaturation at $95^{\circ} \mathrm{C}$ for $2 \mathrm{~min}$; and 40 cycles including 

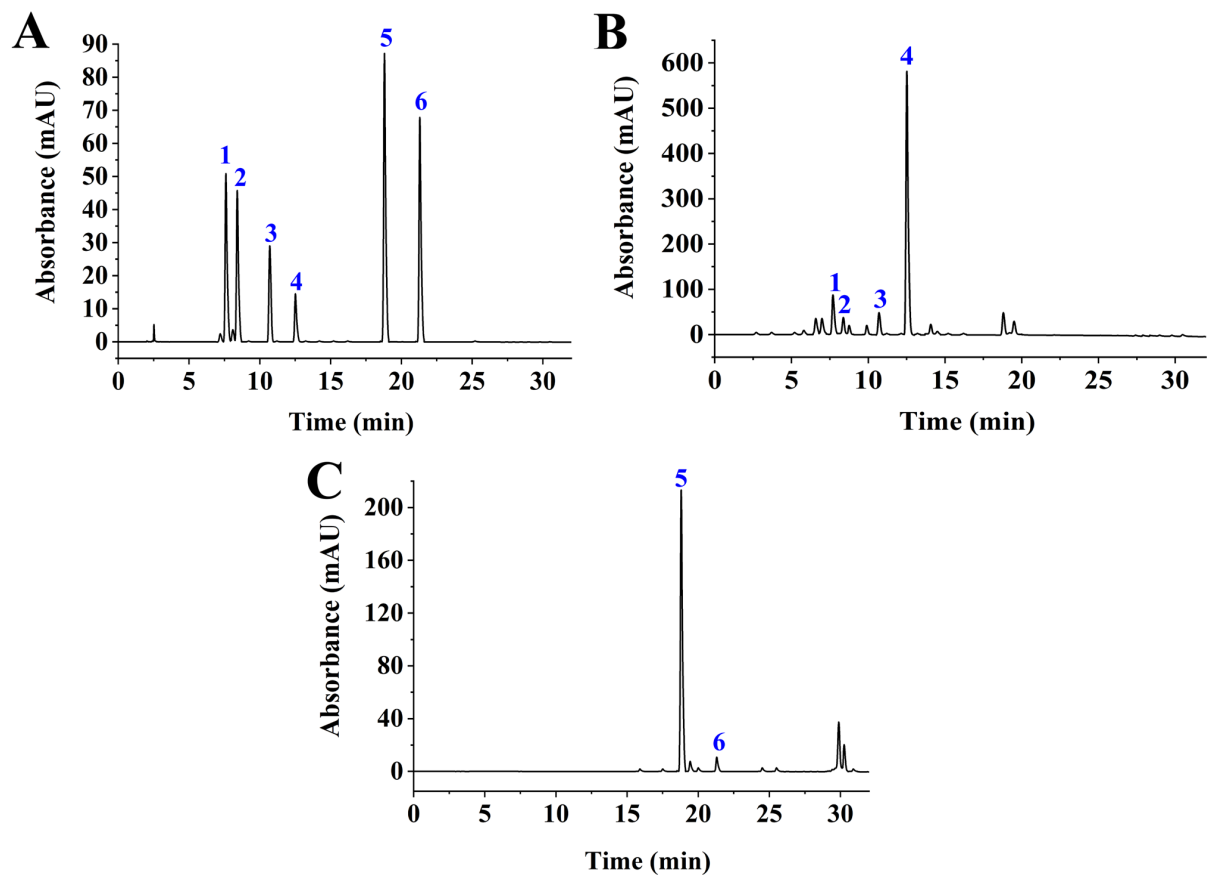

Figure 1. HPLC analysis. (A) HPLC chromatogram of standard compounds: 1, geniposidic acid; 2, deacetylasperulosidic acid; 3, genipin-1-gentiobioside; 4, geniposide; 5, Crocin I; and 6 and Crocin II. (B) HPLC chromatogram of GJE component: 1, geniposidic acid; 2, deacetylasperulosidic acid; 3, genipin-1-gentiobioside; and 4, geniposide were identified with a detection wavelength of $238 \mathrm{~nm}$. (C) HPLC chromatogram of GJE component: 5, Crocin I; and 6, Crocin II were identified at a detection wavelength of $440 \mathrm{~nm}$. HPLC, High-performance liquid chromatography; GJE, Gardenia jasminoides extracts.

denaturation at $95^{\circ} \mathrm{C}$ for $15 \mathrm{sec}$, and annealing at $60^{\circ} \mathrm{C}$. The fluorescence signals were detected at the end of the $60^{\circ} \mathrm{C}$-step. The relative expression was calculated using the $2^{-\Delta \Delta \mathrm{Cq}}$ formula (30). Primers used for RT-qPCR are listed in Tables SI and SII.

ELISA. Following the exposure of ARPE-19 cells to GJE $(5 \mu \mathrm{g} / \mathrm{ml})$, LPS $(5 \mu \mathrm{g} / \mathrm{ml})$ or GJE $(5 \mu \mathrm{g} / \mathrm{ml})$ with LPS $(5 \mu \mathrm{g} / \mathrm{ml})$ for $24 \mathrm{~h}$, the culture media were collected and centrifuged at $12,000 \mathrm{x} g$ for $15 \mathrm{~min}$ at $4^{\circ} \mathrm{C}$. The IL-1 $\beta$, IL- 6 and TNF- $\alpha$ in the supernatants were measured using human Mini ELISA development kits for IL-1ß (cat. no. 900-M95), IL-6 (cat. no. 900-M16) and TNF- $\alpha$ (cat. no. 900-M25) (PeproTech, Inc.).

Statistical analysis. All data are presented as the mean \pm standard error of the mean $(n=6)$. Statistical analysis of the data was performed using GraphPad Prism software version 8 (GraphPad Software, Inc.) by one-way analysis of variance, followed by Dunnett's or Tukey's post hoc test. Linear regression analysis was performed based on the GraphPad Prism 9 Curve Fitting Guide (GraphPad Software, Inc.). $\mathrm{P}<0.05$ was considered to indicate a statistically significant difference.

\section{Results}

Analysis of compounds in GJE. Following microwave-assisted extraction, GJE was subjected to HPLC analysis. Based on six standards, it was found that geniposide and Crocin-1 were the major compounds (Fig. 1), which is in agreement with the results of a recent report (31). The other four compounds, geniposidic acid, deacetylasperulosidic acid, genipin-1-gentiobioside and Crocin II, were also identified in GJE but at low levels. Retention times for geniposide and Crocin I was $12.85 \mathrm{~min}$ and $18.766 \mathrm{~min}$, respectively. Linear regression analyses were performed on the concentration $(\mathrm{X}, \mu \mathrm{g} / \mathrm{ml})$ and the peak area (Y) of geniposide or Crocin I at different concentrations. The regression equations for geniposide and Crocin I were $y=19262073.0848 x-14747.0407$ (Coefficient, 0.9999) and $y=36463016.7557 x+278758.6821$ (coefficient, 0.9992), respectively. The relative standard deviation for precision was $2.31 \%$ (geniposide) and $1.22 \%$ (Crocin I), for repeatability it was $1.59 \%$ (geniposide) and $2.11 \%$ (Crocin I), and for stability it was $1.39 \%$ (geniposide) and $1.58 \%$ (Crocin I). The average recoveries for geniposide and Crocin I were 99.62 and $94.94 \%$, respectively. The contents of geniposide and Crocin I in G. Jasminoides fruits were 40.88 and $7.72 \mathrm{mg} / \mathrm{g}$, respectively.

Effects of LPS and GJE on cell viability. ARPE-19 cells were treated with LPS at concentrations of $0,1.0,2.5,5.0,10.0$ or $20.0 \mu \mathrm{g} / \mathrm{ml}$ for $24 \mathrm{~h}$. MTT assay demonstrated that LPS at 1.0, 2.5 or $5.0 \mu \mathrm{g} / \mathrm{ml}$ had no significant effect on the viability of ARPE-19 cells compared with control cells. However, LPS at higher concentrations $(10.0$ or $20.0 \mu \mathrm{g} / \mathrm{ml})$ was significantly toxic for ARPE-19 cells, and notably decreased cell viability (Fig. 2A). When ARPE-19 cells were treated with GJE at concentrations of $0,5.0,10.0,25.0,50.0$ or $100.0 \mu \mathrm{g} / \mathrm{ml}$, there was no significant difference in cell viability compared with untreated cells (Fig. 2B). Based on these data, LPS at $5.0 \mu \mathrm{g} / \mathrm{ml}$ and GJE at $5.0 \mu \mathrm{g} / \mathrm{ml}$ were selected for further experiments.

GJZ inhibits LPS-induced inflammation in ARPE-19 cells. A total of $5 \mu \mathrm{g} / \mathrm{ml}$ LPS has been used to induce inflammation in AREP-19 cells $(32,33)$. ARPE-19 cells were treated with GJE, LPS or GJE plus LPS for $24 \mathrm{~h}$ and the expression of proinflammatory cytokines was compared. LPS significantly increased the expression of IL-1 $\beta$, IL- 6 and TNF- $\alpha$ in AREP-19 cells compared with control cells, while GJE treatment did not 

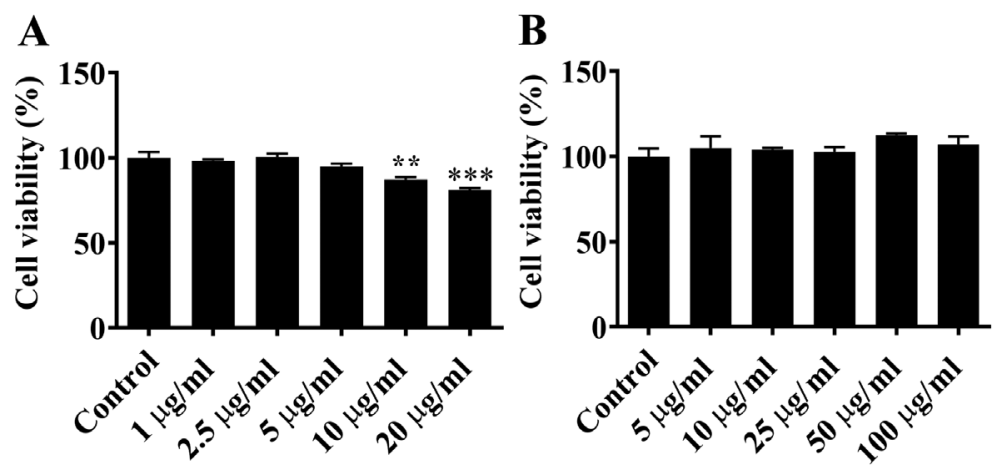

Figure 2. Effects of LPS (A) and GJE (B) on cell viability. The specific concentration of LPS or GJE was used to treat ARPE-19 cells for 24 h, prior to MTT assay being used to measure cell viability, with untreated cells as a control. Data are presented as the mean \pm standard error of the mean and analysed by one-way analysis of variance, followed by Dunnett's post-hoc test. ${ }^{* *} \mathrm{P}<0.01,{ }^{* * *} \mathrm{P}<0.001$. LPS, lipopolysaccharides; GJE, Gardenia jasminoides extracts.
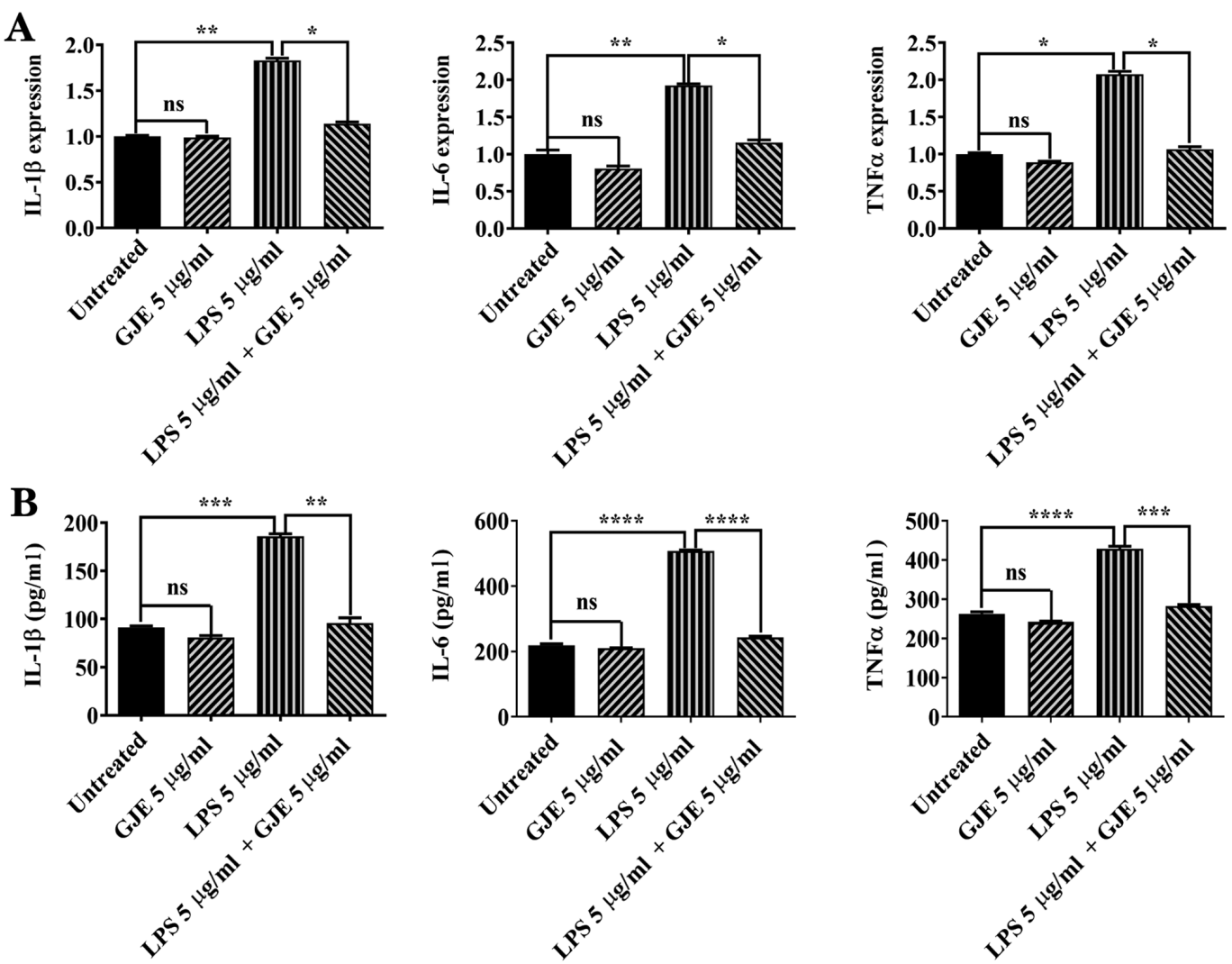

Figure 3. Effects of GJE on the expression of proinflammatory cytokines. (A) mRNA levels of IL-1 $\beta$, IL-6 and TNF- $\alpha$ in treated and untreated cells were measured by reverse transcription-quantitative polymerase chain reaction. (B) Secreted IL-1 $\beta$, IL- 6 and TNF- $\alpha$ protein levels in media of untreated and treated cells were measured using ELISA. Data are presented as the mean \pm standard error of the mean and analyzed using one-way analysis of variance, followed by Tukey's post-hoc test. ${ }^{*} \mathrm{P}<0.05,{ }^{* *} \mathrm{P}<0.01,{ }^{* * *} \mathrm{P}<0.001,{ }^{* * * *} \mathrm{P}<0.0001$. GJE, Gardenia jasminoides extracts; IL, interleukin; TNF, tumor necrosis factor.

cause any changes in expression of these inflammatory mediators. Co-treatment with GJE resulted in markedly decreased expression of these three cytokine genes compared with cells treated with LPS alone (Fig. 3A). Next, ELISA was performed to detect cytokine secretion in control cells and treated cells. LPS exposure significantly increased cytokine secretion, while GJE-treated cells secreted cytokines similarly to control cells. These results suggested that treatment with GJE reversed LPS-induced cytokine secretion (Fig. 3B).

GJE attenuates microphage migration in zebrafish embryos. Previous reports have demonstrated that $\mathrm{CuSO}_{4}$ at $20 \mu \mathrm{M}$ causes primitive macrophage migration to the lateral line in zebrafish embryos (26-28). It was also found that the number of migrated macrophages in treated cells was significantly higher than that in untreated controls. These results indicated that co-treatment significantly decreased macrophage migration (Fig. 4).

GJE reduces inflammation in zebrafish embryos. The present study measured the expression of proinflammatory cytokines in control and treated zebrafish embryos using RT-qPCR. $\mathrm{CuSO} 4$ treatment resulted in significantly increased expression of IL-1 $\beta$, IL6 and TNF $\alpha$ cytokines compared with that 
A

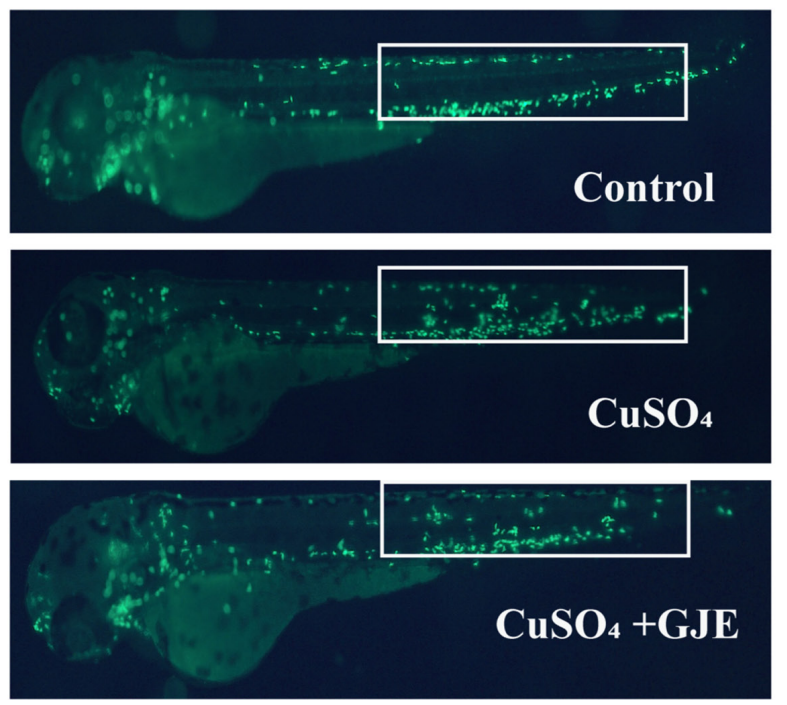

B

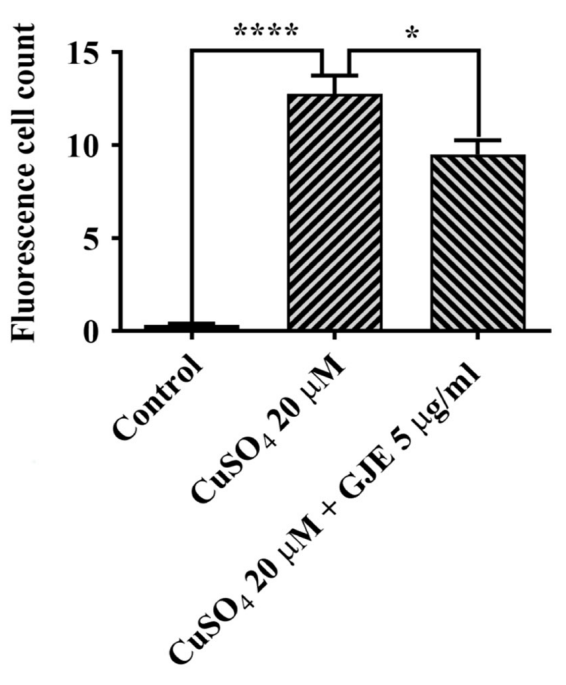

Figure 4. GJE inhibits $\mathrm{CuSO}_{4}$-induced primitive macrophage migration in transgenic zebrafish (Tg:zlyz-EGFP) embryos; magnification, x100. (A) Representative images of control and treated zebrafish embryos. (B) Macrophages in the regions of interest (white boxes) were quantified. Data are presented as the mean \pm standard error of the mean and analysed using one-way analysis of variance, followed by Tukey's post-hoc test. ${ }^{*} \mathrm{P}<0.05$, ${ }^{* * * * *} \mathrm{P}<0.0001$. GJE, Gardenia jasminoides extracts; IL, interleukin; TNF, tumour necrosis factor; LPS, lipopolysaccharides.

A

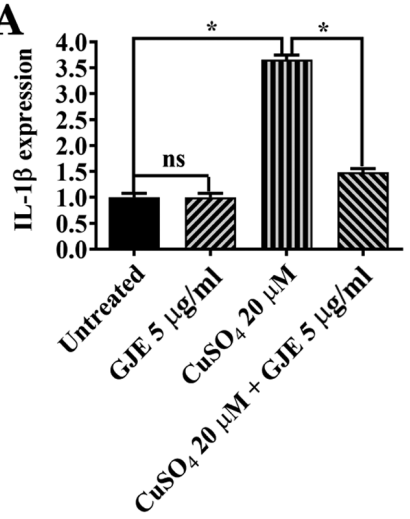

B

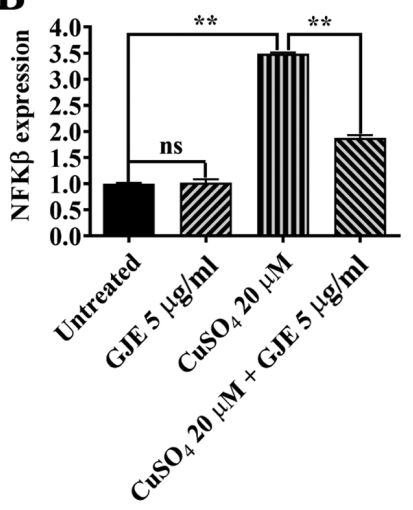

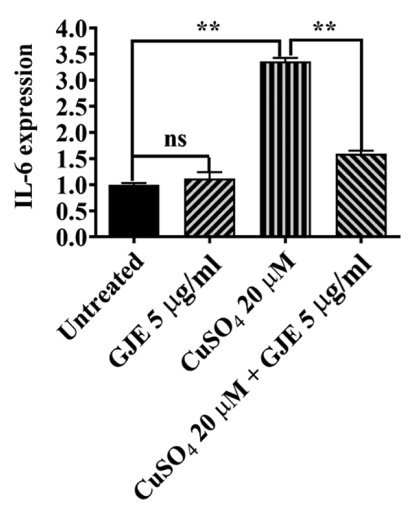
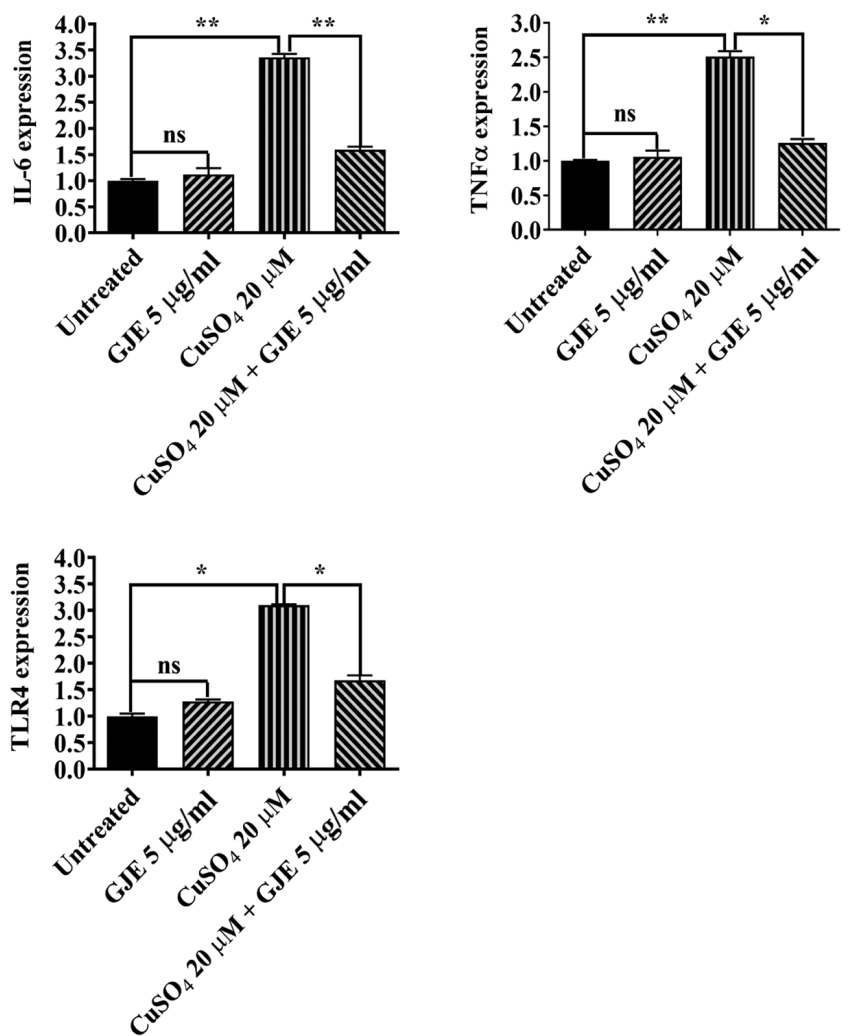

Figure 5. Effects of GJE on inflammation via the TLR4 signaling pathway in $\mathrm{CuSO}_{4}$-treated zebrafish embryos. (A) mRNA levels of IL-1 $\beta$, IL-6 and TNF- $\alpha$ in treated and untreated embryos were measured by reverse transcription-quantitative polymerase chain reaction. (B) Expression levels of of NFK $\beta$ and TLR4 in untreated or treated embryos were measured by qRT-PCR. Data are presented as the mean \pm standard error of the mean and analyzed using one-way analysis of variance, followed by Tukey's post-hoc test. ${ }^{*} \mathrm{P}<0.05,{ }^{* *} \mathrm{P}<0.01$. GJE, Gardenia jasminoides extracts; TLR4, toll-like receptor 4; ns, no significance; IL, interleukin; TNF, tumor necrosis factor; LPS, lipopolysaccharides.

of controls, while GJE did not cause any alteration in expression of these cytokines. The embryos co-exposed to the two compounds had a significantly decreased expression of cytokines compared with embryos exposed to $\mathrm{CuSO}_{4}$ alone (Fig. 5A). The effects of LPS or LPS plus GJE were investigated in zebrafish embryos. Similar to the in vitro results in 

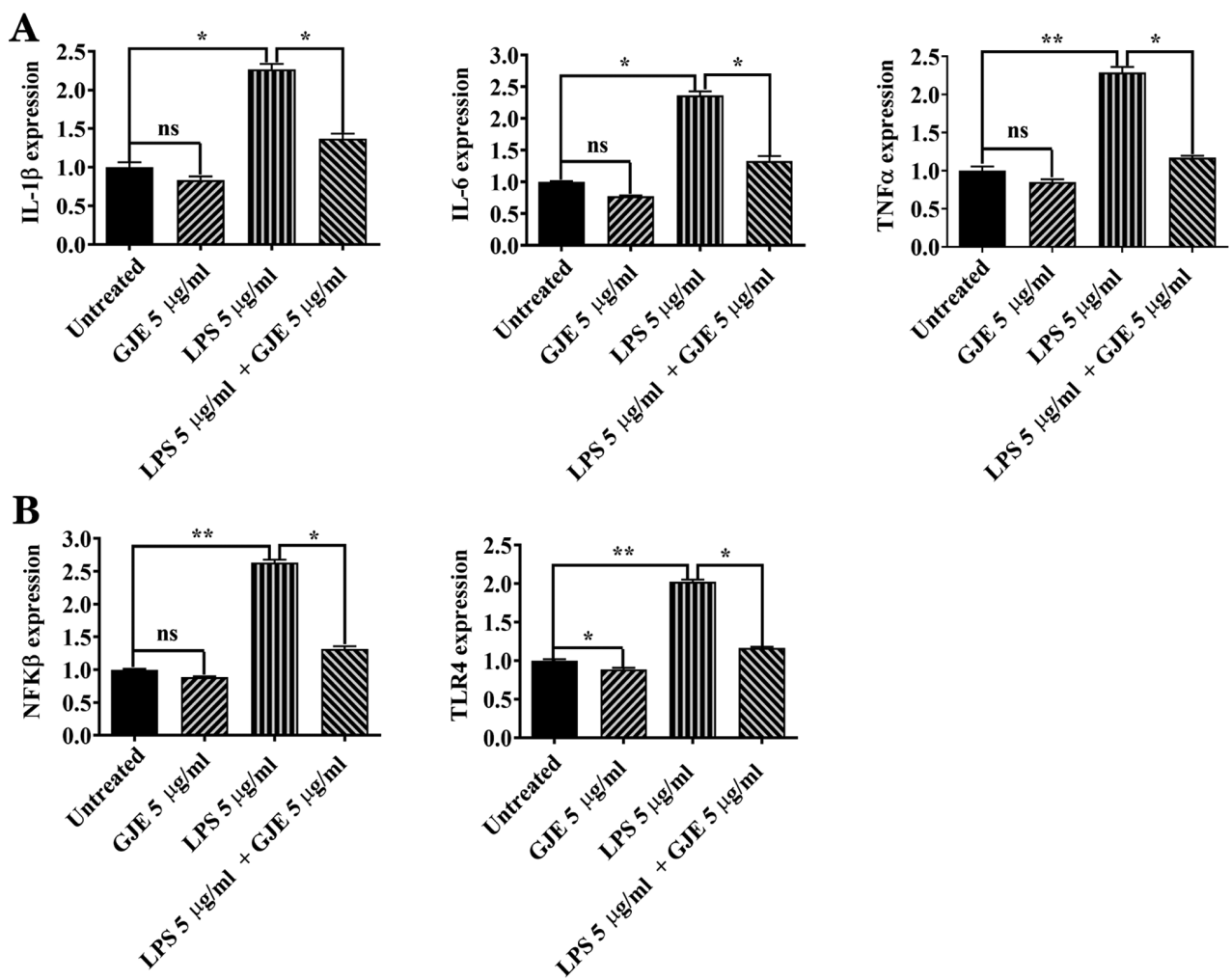

Figure 6. Effects of GJE on inflammation via the TLR4 signaling pathway in LPS-treated zebrafish embryos. GJE decreased LPS-induced expression of proinflammatory cytokine genes (A), attenuated LPS-induced expression of NFK $\beta$ activating protein and decreased LPS-induced TLR4 expression (B). Data are presented as the mean \pm standard error of the mean and analyzed using one-way analysis of variance, followed by Tukey's post-hoc test. " $\mathrm{P}<0.05$, ${ }^{* *} \mathrm{P}<0.01$. GJE, Gardenia jasminoides extracts; TLR4, toll-like receptor 4; ns, no significance; IL, interleukin; TNF, tumor necrosis factor; LPS, lipopolysaccharides.

ARPE-19 cells, LPS significantly increased the expression of IL- $1 \beta$, IL- 6 and TNF $\alpha$, while GJE treatment counteracted LPS-induced effects on the expression of the three genes (Fig. 6A).

The NFkB signaling pathway serves a central role in regulating inflammation (34). Therefore, the present study investigated the NFKB activating protein (nkap) expression by RT-qPCR. The results of the present study suggested that $\mathrm{CuSO}_{4}$ and LPS markedly enhanced nkap expression compared with that of control zebrafish embryos. Additionally, co-treatment with GJE resulted in significantly decreased expression of nkap compared with the embryos exposed to $\mathrm{CuSO}_{4}$ or LPS alone (Figs. 5B and 6B). Finally, activation of the Toll-like receptor 4 (TLR4) signaling pathway induces the nuclear translocation of NF- $\mathrm{KB}$ and leads to upregulation of proinflammatory cytokines (35). The present study found higher expression of $t l r 4 b$ in $\mathrm{CuSO}_{4}$ or LPS-treated embryos that were significantly counteracted by co-treatment with GJE (Figs. 5B and 6B).

\section{Discussion}

Inhibition of inflammatory agents represents an effective therapeutic strategy to treat AMD (36). There are numerous natural products, which are rich in anti-inflammatory compounds. In GJE, six predominant compounds, including geniposidic acid, deacetylasperulosidic acid, genipin-1-gentiobioside, geniposide, Crocin I and II, were identified and the anti-inflammatory potential of GJE was confirmed in vitro and in vivo. The attenuated expression of proinflammatory cytokines is associated with GJE-evoked inhibition of the TLR4-mediated signal pathway, given that expression of TLR 4 and NKAP were revealed to be downregulated.

Numerous active compounds have been identified in G. Jasminoides, including iridoids, iridoid glycosides, terpenoids and phenolic acids (36). While geniposide and Crocin I were the predominant compounds in GJE, geniposidic acid, deacetylasperulosidic acid, genipin-1-gentiobioside and Crocin II were also detected at a low level in GJE (Fig. 1). The anti-inflammatory characteristics of the whole GJE and its individual active components have been widely studied $(22,37)$. An early study reported the anti-inflammatory capacity of ethanol-based extracts of G. Jasminoides in inhibiting carrageenan-induced rat paw oedema and acetic acid-induced vascular permeability (38). Hwang et al (39) reported that GJE decreased vascular inflammation in TNF- $\alpha$ treated human umbilical vein endothelial cells via preventing NF-kB p65 nuclear translocation, downregulating adhesion molecule expression and decreasing monocyte-endothelial cell interaction (39). GJE was also reported to decrease LPS-induced production of IL-1 $\beta$, IL-6 and nitric oxide in microglial BV2 cells through inactivation of the MAPK signalling pathway (40). Geniposide, the main functional compound of G. Jasminoides, has shown strong anti-inflammatory activity in vitro and in vivo. For example, it significantly decreased the production of IL-1 $\beta$, 
IL-6 and TNF- $\alpha$, decreased expression and translocation of $\mathrm{NF}-\kappa \mathrm{B}$ p65, and inhibited the MAPK signalling pathway in rat primary microglia exposed to oxygen-glucose deprivation (41). Geniposide also showed similar protective effects in LPS-exposed macrophages and in mice challenged with LPS (42). Crocin, another active compound identified in G. Jasminoides, also showed anti-inflammatory activity by decreasing the expression of proinflammatory cytokines and decreasing nitric oxide production $(43,44)$.

In the present study, G. Jasminoides components demonstrated a protective effect against retinal damage. Crocin and genipin (a metabolite of geniposide) protect ARPE-19 cells from $\mathrm{H}_{2} \mathrm{O}_{2}$-caused oxidative damage by decreasing the production of reactive oxygen species and inhibiting Caspase 3-mediated apoptosis via the NRF2 signalling pathway $(45,46)$. Crocin may decrease $\mathrm{H}_{2} \mathrm{O}_{2}$-induced RGC-5 ganglion cell death by inhibiting oxidative stress and apoptosis, and reversing NF- $\kappa \mathrm{B}$ activation (47). Crocin may also increase the survival of rat ganglion cells following ischemia/reperfusion injury and protect photoreceptors from blue-light damage in cultured bovine and primate retinas (48-50). Recently, a clinical trial showed that Crocin (15 mg/day for three months) resulted in a decrease in glycated haemoglobin (HbA1c) and in central macula thickness, and result in an improvement of the best-corrected visual acuity in patients with diabetic maculopathy (51). Crocetin, another active compound identified in G. Jasminoides, protected ganglion cells against $\mathrm{H}_{2} \mathrm{O}_{2}$-induced oxidative damage and prevent photoreceptor degeneration from light-induced damage (52). Crocetins also inhibit retinal damage from ischemia/reperfusion injury or from N-methyl-D-aspartate-induced toxicity via blocking Caspase and NFkB pathways $(53,54)$. Recently, Nitta et al (55) reported that crocetin prevented retinal edema in a laser-induced retinal vein occlusion mouse model via downregulating the expression of MMP-9 and TNF- $\alpha$. Given the multifaceted anti-inflammatory impact of GJE treatment in vitro and in vivo reported in the present study, it is likely that the combination of active compounds may evoke more profound effects than any single-compound treatment. The optimum dose of these compounds may be even more effective and require further investigation.

The results of the present study were based on an in vitro RPE model and zebrafish embryo inflammation models, which may not be directly relevant to an in vivo AMD study. Further studies will be required to investigate the anti-inflammatory role of GJE in preclinical AMD models to further verify the results of the current study. In addition, it is valuable to gain more insights into the molecular mechanisms of GJE's protection in vivo.

In summary, the results of the present study demonstrated the anti-inflammatory role of GJE in RPE cells and in zebrafish embryos. Given that it is a natural product with a long history in Traditional Chinese Medicine, GJE appears to have therapeutic potential for treating patients with AMD and could be easily translated to the clinics.

\section{Acknowledgements}

Not applicable.

\section{Funding}

The present study was funded by the Department of Education, Hunan, China (grant no. 19A045); the Hunan Province 'Help Our Motherland Through Elite Intellectual Resources from Overseas' program to ZZ (grant no. 60802); and a Hunan Provincial Natural Science Foundation of China (grant no. 2020JJ4641) to JC. The study was partially supported by the Rosetrees Trust (grant nos. M160, M160-F1 and M160-F2), National Eye Research Centre (grant no. SAC037) and the Lotus Scholarship Program of Hunan Province (2019) to XS.

\section{Availability of data and materials}

The datasets used and/or analyzed during the current study are available from the corresponding author on reasonable request.

\section{Authors' contributions}

XS and ZZ designed the experiments. JC, GMT, XZ, WT, FL, $\mathrm{ML}$ and $\mathrm{CZ}$ performed the experiments. JC, GMT and XZ analyzed the data. XS and ZZ wrote the manuscript. XS and ZZ confirmed the authenticity of the raw data. All authors read and approved the final manuscript.

\section{Ethics approval and consent to participate}

All the animal experimental procedures were approved by the Animal Ethics and Welfare Committee, Glasgow Caledonian University (Project License PPL 60/4169).

\section{Patient consent for publication}

Not applicable.

\section{Competing interests}

The authors declare that they have no competing interests.

\section{References}

1. Mantel I: Age-related macular degeneration-a challenge for public health care. Ther Umsch 73: 79-83, 2016 (In German).

2. Wong WL, Su X, Li X, Cheung CM, Klein R, Cheng CY and Wong TY: Global prevalence of age-related macular degeneration and disease burden projection for 2020 and 2040: A systematic review and meta-analysis. Lancet Glob Health 2: e106-e116, 2014.

3. Age-Related Eye Disease Study Research Group: A randomized, placebo-controlled, clinical trial of high-dose supplementation with vitamins $C$ and $E$, beta carotene, and zinc for age-related macular degeneration and vision loss: AREDS report no. 8. Arch Ophthalmol 119: 1417-1436, 2001.

4. Jager RD, Mieler WF and Miller JW: Age-related macular degeneration. N Engl J Med 358: 2606-2617, 2008.

5. Yuan A and Kaiser PK: Emerging therapies for the treatment of neovascular age related macular degeneration. Semin Ophthalmol 26: 149-155, 2011.

6. Datta S, Cano M, Ebrahimi K, Wang L and Handa JT: The impact of oxidative stress and inflammation on RPE degeneration in non-neovascular AMD. Prog Retin Eye Res 60: 201-218, 2017.

7. Krogh Nielsen M, Subhi Y, Molbech CR, Falk MK, Nissen MH and Sørensen TL: Systemic levels of interleukin-6 correlate with progression rate of geographic atrophy secondary to age-related macular degeneration. Invest Ophthalmol Vis Sci 60: 202-208, 2019. 
8. Subhi Y, Krogh Nielsen M, Molbech CR, Oishi A, Singh A, Nissen MH and Sørensen TL: Plasma markers of chronic low-grade inflammation in polypoidal choroidal vasculopathy and neovascular age-related macular degeneration. Acta Ophthalmol 97: 99-106, 2019.

9. Liu F, Ding X, Yang Y, Li J, Tang M, Yuan M, Hu A, Zhan Z, $\mathrm{Li} \mathrm{Z}$ and $\mathrm{Lu} \mathrm{L}$ : Aqueous humor cytokine profiling in patients with wet AMD. Mol Vis 22: 352-361, 2016

10. Wang Y, Hanus JW, Abu-Asab MS, Shen D, Ogilvy A, Ou J, Chu XK, Shi G, Li W, Wang S and Chan CC: NLRP3 upregulation in retinal pigment epithelium in age-related macular degeneration. Int J Mol Sci 17: 73, 2016.

11. Sivaprasad S, Adewoyin T, Bailey TA, Dandekar SS, Jenkins S, Webster AR and Chong NV: Estimation of systemic complement $\mathrm{C} 3$ activity in age-related macular degeneration. Arch Ophthalmol 125: 515-519, 2007.

12. Scholl HP, Charbel Issa P, Walier M, Janzer S, Pollok-Kopp B, Börncke F, Fritsche LG, Chong NV, Fimmers R, Wienker T, et al: Systemic complement activation in age-related macular degeneration. PLoS One 3: e2593, 2008.

13. Reynolds R, Hartnett ME, Atkinson JP, Giclas PC, Rosner B and Seddon JM: Plasma complement components and activation fragments: Associations with age-related macular degeneration genotypes and phenotypes. Invest Ophthalmol Vis Sci 50: 5818-5827, 2009.

14. Machalińska A, Dziedziejko V, Mozolewska-Piotrowska K, Karczewicz D, Wiszniewska B and Machaliński B: Elevated plasma levels of $\mathrm{C} 3$ a complement compound in the exudative form of age-related macular degeneration. Ophthalmic Res 42: 54-59, 2009.

15. Alhasani RH, Biswas L, Tohari AM, Zhou X, Reilly J, He JF and Shu X: Gypenosides protect retinal pigment epithelium cells from oxidative stress. Food Chem Toxicol 112: 76-85, 2018.

16. Tohari AM, Alhasani RH, Biswas L, Patnaik SR, Reilly J, Zeng Z and Shu X: Vitamin D attenuates oxidative damage and inflammation in retinal pigment epithelial cells. Antioxidants (Basel) 8 : $341,2019$.

17. Kauppinen A, Paterno JJ, Blasiak J, Salminen A and Kaarniranta K: Inflammation and its role in age-related macular degeneration. Cell Mol Life Sci 73: 1765-1786, 2016.

18. Biswas L, Zhou X, Dhillon B, Graham A and Shu X: Retinal pigment epithelium cholesterol efflux mediated by the $18 \mathrm{kDa}$ translocator protein, TSPO, a potential target for treating age-related macular degeneration. Hum Mol Genet 26: 4327-4339, 2017

19. Gnanaguru G, Choi AR, Amarnani D and D'Amore PA: Oxidized lipoprotein uptake through the CD36 receptor activates the NLRP3 inflammasome in human retinal pigment epithelial cells. Invest Ophthalmol Vis Sci 57: 4704-4712, 2016.

20. Larrayoz IM, Huang JD, Lee JW, Pascual I and Rodríguez IR: 7-Ketocholesterol-induced inflammation: Involvement of multiple kinase signaling pathways via $N F \kappa B$ but independently of reactive oxygen species formation. Invest Ophthalmol Vis Sci 51: 4942-4955, 2010.

21. Yang C, Xie L, Gu Q, Qiu Q, Wu X and Yin L: 7-Ketocholesterol disturbs RPE cells phagocytosis of the outer segment of photoreceptor and induces inflammation through ERK signaling pathway. Exp Eye Res 189: 107849, 2019.

22. Chen L, Li M, Yang Z, Tao W, Wang P, Tian X, Li X and Wang W: Gardenia jasminoides Ellis: Ethnopharmacology, phytochemistry, and pharmacological and industrial applications of an important traditional Chinese medicine. J Ethnopharmacol 257: $112829,2020$.

23. National Commission of Pharmacopoeia: Pharmacopoeia of the People's Republic of China, Vol. 1. China Medical Science and Technology Press, Beijing, pp231, 2010.

24. Song X, Zhang W, Wang T, Jiang H, Zhang Z, Fu Y, Yang Z, Cao Y and Zhang N: Geniposide plays an anti-inflammatory role via regulating TLR4 and downstream signaling pathways in lipopolysaccharide-induced mastitis in mice. Inflammation 37: $1588-1598,2014$.

25. Zhang Y, Bai XT, Zhu KY, Jin Y, Deng M, Le HY, Fu YF, Chen Y, Zhu J, Look AT, et al: In vivo interstitial migration of primitive macrophages mediated by JNK-matrix metalloproteinase 13 signaling in response to acute injury. J Immunol 181: 2155-2164, 2008.

26. Li JJ, Zhang Y, Han LW, Tian QP, He QX, Wang XM, Sun C, Han J and Liu KC: Tenacissoside $\mathrm{H}$ exerts an anti-inflammatory effect by regulating the NF- $\mathrm{NB}$ and $\mathrm{p} 38$ pathways in zebrafish. Fish Shellfish Immunol 83: 205-212, 2018.
27. Zhang Y, Wang C, Jia ZL, Ma RJ, Wang XF, Chen WY and Liu KC: Isoniazid promotes the anti-inflammatory response in zebrafish associated with regulation of the PPAR $\gamma / \mathrm{NF}-\kappa \mathrm{B} / \mathrm{AP}-1$ pathway. Chem Biol Interact 316: 108928, 2020.

28. Zhou H, Cao H, Zheng Y, Lu Z, Chen Y, Liu D, Yang H, Quan J, Huo C, Liu J and Yu L: Liang-Ge-San, a classic traditional Chinese medicine formula, attenuates acute inflammation in zebrafish and RAW 264.7 cells. J Ethnopharmacol 249: 112427, 2020.

29. Zhang Y, Takagi N, Yuan B, Zhou Y, Si N, Wang H, Yang J, Wei X, Zhao $\mathrm{H}$ and Bian B: The protection of indolealkylamines from LPS-induced inflammation in zebrafish. J Ethnopharmacol 243: $112122,2019$.

30. Livak KJ and Schmittgen TD: Analysis of relative gene expression data using real-time quantitative PCR and the 2(-Delta Delta C(T)) method. Methods 25: 402-408, 2001

31. Shan MQ, Wang TJ, Jiang YL, Yu S, Yan H, Zhang L, Wu QN, Geng T, Huang WZ, Wang ZZ and Xiao W: Comparative analysis of sixteen active compounds and antioxidant and anti-influenza properties of Gardenia jasminoides fruits at different times and application to the determination of the appropriate harvest period with hierarchical cluster analysis. J Ethnopharmacol 233: $169-178,2019$.

32. Ozal SA, Turkekul K, Gurlu V, Guclu H and Erdogan S: Esculetin protects human retinal pigment epithelial cells from lipopolysaccharide-induced inflammation and cell death. Curr Eye Res 43 1169-1176, 2018

33. Tao L, Qiu Y, Fu X, Lin R, Lei C, Wang J and Lei B Angiotensin-converting enzyme 2 activator diminazene aceturate prevents lipopolysaccharide-induced inflammation by inhibiting MAPK and NF- $\mathrm{KB}$ pathways in human retinal pigment epithelium. J Neuroinflammation 13: 35, 2016.

34. Duan X, Gao S, Li J, Wu L, Zhang Y, Li W, Zhao L, Chen J, Yang S, Sun G and Li B: Acute arsenic exposure induces inflammatory responses and $\mathrm{CD} 4^{+} \mathrm{T}$ cell subpopulations differentiation in spleen and thymus with the involvement of MAPK, NF- $\kappa \mathrm{B}$, and Nrf2. Mol Immunol 81: 160-172, 2017.

35. Vaure C and Liu Y: A comparative review of toll-like receptor 4 expression and functionality in different animal species. Front Immunol 5: 316, 2014

36. Wang L, Schmidt S, Larsen PP, Meyer JH, Roush WR, Latz E, Holz FG and Krohne TU: Efficacy of novel selective NLRP3 inhibitors in human and murine retinal pigment epithelial cells. J Mol Med (Berl) 97: 523-532, 2019.

37. Su Q, Yao J and Sheng C: Geniposide attenuates LPS-induced injury via up-regulation of miR-145 in H9c2 cells. Inflammation 41: 1229-1237, 2018

38. Koo HJ, Lim KH, Jung HJ and Park EH: Anti-inflammatory evaluation of gardenia extract, geniposide and genipin. J Ethnopharmacol 103: 496-500, 2006.

39. Hwang SM, Lee YJ, Yoon JJ, Lee SM, Kang DG and Lee HS: Gardenia jasminoides inhibits tumor necrosis factor-alpha-induced vascular inflammation in endothelial cells. Phytother Res 24 (Suppl 2): S214-S219, 2010.

40. Lin WH, Kuo HH, Ho LH, Tseng ML, Siao AC, Hung CT, Jeng KC and Hou CW: Gardenia jasminoides extracts and gallic acid inhibit lipopolysaccharide-induced inflammation by suppression of JNK2/1 signaling pathways in BV-2 cells. Iran J Basic Med Sci 18: 555-562, 2015

41. Wang J, Hou J, Zhang P, Li D, Zhang C and Liu J: Geniposide reduces inflammatory responses of oxygen-glucose deprived rat microglial cells via inhibition of the TLR4 signaling pathway. Neurochem Res 37: 2235-2248, 2012.

42. Fu Y, Liu B, Liu J, Liu Z, Liang D, Li F, Li D, Cao Y, Zhang X, Zhang N and Yang Z: Geniposide, from Gardenia jasminoides Ellis, inhibits the inflammatory response in the primary mouse macrophages and mouse models. Int Immunopharmacol 14: 792-798, 2012

43. Nam KN, Park YM, Jung HJ, Lee JY, Min BD, Park SU, Jung WS, Cho KH, Park JH, Kang I, et al: Anti-inflammatory effects of crocin and crocetin in rat brain microglial cells. Eur J Pharmacol 648: 110-116, 2010.

44. Yorgun MA, Rashid K, Aslanidis A, Bresgen C, Dannhausen K and Langmann T: Crocin, a plant-derived carotenoid, modulates microglial reactivity. Biochem Biophys Rep 12: 245-250, 2017.

45. Kassumeh S, Wertheimer CM, Ohlmann A, Priglinger SG and Wolf A: Cytoprotective effect of crocin and trans-resveratrol on photodamaged primary human retinal pigment epithelial cells. Eur J Ophthalmol: 1120672119895967, 2019. 
46. Zhao $\mathrm{H}$, Wang $\mathrm{R}$, Ye $\mathrm{M}$ and Zhang L: Genipin protects against $\mathrm{H}_{2} \mathrm{O}_{2}$-induced oxidative damage in retinal pigment epithelial cells by promoting Nrf2 signaling. Int J Mol Med 43: 936-944, 2019.

47. Lv B, Chen T, Xu Z, Huo F, Wei Y and Yang X: Crocin protects retinal ganglion cells against $\mathrm{H}_{2} \mathrm{O}_{2}$-induced damage through the mitochondrial pathway and activation of NF- $\mathrm{KB}$. Int J Mol Med 37: 225-232, 2016

48. Chen L, Qi Y and Yang X: Neuroprotective effects of crocin against oxidative stress induced by ischemia/reperfusion injury in rat retina. Ophthalmic Res 54: 157-168, 2015.

49. Qi Y, Chen L, Zhang L, Liu WB, Chen XY and Yang XG: Crocin prevents retinal ischaemia/reperfusion injury-induced apoptosis in retinal ganglion cells through the PI3K/AKT signalling pathway. Exp Eye Res 107: 44-51, 2013.

50. Laabich A, Vissvesvaran GP, Lieu KL, Murata K, McGinn TE, Manmoto CC, Sinclair JR, Karliga I, Leung DW, Fawzi A and Kubota R: Protective effect of crocin against blue light- and white light-mediated photoreceptor cell death in bovine and primate retinal primary cell culture. Invest Ophthalmol Vis Sci 47: 3156-3163, 2006.

51. Sepahi S, Mohajeri SA, Hosseini SM, Khodaverdi E, Shoeibi N, Namdari M and Tabassi SAS: Effects of crocin on diabetic maculopathy: A placebo-controlled randomized clinical trial. Am J Ophthalmol 190: 89-98, 2018.
52. Yamauchi M, Tsuruma K, Imai S, Nakanishi T, Umigai N, Shimazawa M and Hara H: Crocetin prevents retinal degeneration induced by oxidative and endoplasmic reticulum stresses via inhibition of caspase activity. Eur J Pharmacol 650: 110-119, 2011.

53. Ohno Y, Nakanishi T, Umigai N, Tsuruma K, Shimazawa M and Hara H: Oral administration of crocetin prevents inner retinal damage induced by $\mathrm{N}$-methyl-D-aspartate in mice. Eur J Pharmacol 690: 84-89, 2012.

54. Ishizuka F, Shimazawa M, Umigai N, Ogishima H, Nakamura S, Tsuruma $\mathrm{K}$ and Hara $\mathrm{H}$ : Crocetin, a carotenoid derivative, inhibits retinal ischemic damage in mice. Eur J Pharmacol 703: 1-10, 2013.

55. Nitta K, Nishinaka A, Hida Y, Nakamura S, Shimazawa M and Hara H: Oral and ocular administration of crocetin prevents retinal edema in a murine retinal vein occlusion model. Mol Vis 25: 859-868, 2019.

This work is licensed under a Creative Commons Attribution-NonCommercial-NoDerivatives 4.0 International (CC BY-NC-ND 4.0) License. 